\title{
Interspecific hybridization in the genus Hieracium s. str.: evidence for bidirectional gene flow and spontaneous allopolyploidization
}

\author{
Patrik Mráz $\cdot$ Jindřich Chrtek · Judith Fehrer
}

Received: 20 July 2010/ Accepted: 22 November 2010/Published online: 5 April 2011

(C) Springer-Verlag 2011

\begin{abstract}
Although reticulation has indisputably played an important role in the evolutionary history of the genus $\mathrm{Hi}$ eracium s. str. (Asteraceae), convincingly documented cases of recent interspecific hybridization are very rare. Here we report combined evidence on recent hybridization between two diploid species, Hieracium alpinum and H. transsilvanicum. The hybrid origin of the plants from the Romanian Eastern Carpathians was supported by additive patterns of nuclear ribosomal DNA polymorphism (ITS), an intermediate position of hybrid plants in principal coordinate analysis based on amplified fragment length polymorphism phenotypes (AFLP), and additivity at one allozyme locus. Flow cytometric analyses and chromosome counting showed that two hybrids were diploid $(2 \mathrm{n} \sim 2 \mathrm{x} \sim 18)$ while one was surprisingly tetraploid $(2 \mathrm{n}=4 \mathrm{x}=36)$. To our knowledge, this is the first record of spontaneous polyploidization following interspecific crossing in the genus. Allozyme data,
\end{abstract}

P. Mráz

Laboratoire d'Ecologie Alpine, UMR UJF-CNRS 5553,

Université Joseph Fourier, PO Box 53,

38041 Grenoble Cedex 9, France

Present Address:

P. Mráz ( $\square)$

Department of Biology, Unit of Ecology and Evolution,

University of Fribourg, Chemin du Musée 10,

1700 Fribourg, Switzerland

e-mail: patrik.mraz@unifr.ch

J. Chrtek · J. Fehrer

Institute of Botany, Academy of Sciences of the Czech Republic, 25243 Průhonice, Czech Republic

J. Chrtek

Department of Botany, Faculty of Science, Charles University, 12801 Praha, Czech Republic especially the presence of unbalanced heterozygosity at one locus, suggest the origin of this tetraploid via a triploid bridge with subsequent backcrossing to $H$. alpinum. According to PCR-RFLP analyses of the trnT-trnL intergenic spacer, all $H$. $\times$ krasani hybrids examined had the $H$. alpinum haplotype while $H$. transsilvanicum served as a pollen donor. The hybrids occurred at the locality with abundant $H$. alpinum plants where paternal $H$. transsilvanicum was missing. Previously reported instances of interspecific hybridization between the same parental taxa showed an opposite direction of crossing and relative abundance of parental taxa. This suggests that the direction of hybridization might be influenced by the frequency of parental taxa at the locality.

Keywords Additive polymorphism - AFLP · Allozymes · Asteraceae · Chromosome number · nrITS · Flow cytometry $\cdot$ Hybridization · Polyploidization

\section{Introduction}

Hieracium L. s.str. (i.e., without Pilosella Hill) is a speciesrich Holarctic hawkweed genus. Most of the so far analyzed Hieracium taxa are tri- or tetraploid apomicts $(2 \mathrm{n}=3 \mathrm{x} / 4 \mathrm{x}=27 / 36$, based on $\mathrm{x}=9)$, while sexual diploid species $(2 \mathrm{n}=2 \mathrm{x}=18)$ are rare and most of them are confined to southern latitudes (Merxmüller 1975; Schuhwerk 1996; Chrtek et al. 2004, 2007; Tyler and Jönsson 2009). Morphological (Zahn 1921-1923) and molecular patterns of variation (Fehrer et al. 2009) suggest very extensive interspecific hybridization. However, the reticulation has mostly taken place in the past (Fehrer et al. 2009), and there is almost no evidence of recent interspecific gene flow (Mráz et al. 2005). Thus, any documented case of recent hybridization is of high interest because it 
might help to better understand ancient hybridization processes in this genus.

Only two incidences of natural recent hybridization have been documented so far in the genus Hieracium (Mráz et al. 2005; Chrtek et al. 2006). In both cases, only diploid parental taxa were involved, although crossing between diploid and polyploid cytotypes is possible as was demonstrated by experimental crossing (Mráz 2003; Mráz and Tomčíková 2004). There are several reasons why recent interspecific hybridization is rare in the genus: (1) The few diploid species are usually geographically and/or ecologically allopatric, and thus possible interspecific gene flow is strongly limited. Moreover, even in the rare cases of sympatric occurrence of diploid species, the frequency of hybridization might be decreased due to induced autogamy (so-called mentor effect) of otherwise strictly self-incompatible taxa (Mráz 2003; Mráz and Paule 2006). (2) In polyploid taxa, hybridization is strongly constrained due to agamospermic reproduction (autonomous diplospory of the Antennaria type, Gustafsson 1946). This breeding system is considered as obligate in Hieracium polyploids. Moreover, it seems that fertilization is highly improbable in polyploids because embryo formation already starts before flower opening (so-called precocious embryony, Skawińska 1963; Nogler 1984). Thus, interspecific pollen has literally no chance to fecundate an unreduced egg cell in polyploid plants. According to this, Hieracium polyploids have only limited possibility, if any, to play some role in hybridization as maternal (seed) plants. Nevertheless, many Hieracium polyploids are still able to produce some amount of pollen and might therefore contribute to gene flow as pollen donors (Mráz et al. 2002, 2009; Slade and Rich 2007). Indeed, some viable hybrid progeny have been obtained during experimental crosses between diploid taxa serving as maternal plants and apomictic polyploids as pollen donors (Mráz 2003; Mráz and Tomčíková 2004). However, also in this type of cross, the mentor effect reduced the hybridization rate substantially (Mráz 2003; Mráz and Tomčíková 2004).

Hieracium $\times$ krasani Woł. (H. alpinum L. $\times H$. transsilvanicum Heuff.) and $H . \times$ grofae Woł. ( $H$. alpinum $\times H$. umbellatum L.) are the only convincingly documented recent hybrids in the genus (Mráz et al. 2005; Chrtek et al. 2006). These rare diploid hybrids were found in the Romanian and Ukrainian Eastern Carpathians where their parental diploid taxa, though ecologically vicariant, co-occur. Although the hybrid plants did not differ in pollen size and pollen production from their parents, they were completely seed sterile (Mráz et al. 2005; Chrtek et al. 2006). Analyses of plastid DNA in the diploid nothotaxon $H$. $\times$ krasani revealed that the maternal plant was $H$. transsilvanicum and the pollen donor was $H$. alpinum in both populations analyzed (Mráz et al. 2005). At both localities, single $H . \times$ krasani plants were found at places where $H$. transsilvanicum was abundant while H. alpinum was either extremely rare or completely absent. In such a situation, one might have expected that $H$. alpinum was the seed parent because of a putative excess of H. transsilvanicum pollen. In 2004, during a botanical excursion to Mt. Bogolin (Mţii Bistriței) in the Romanian Eastern Carpathians, we found several plants morphologically similar to $H$. $\times$ krasani. Interestingly, the putative hybrids were intermingled with hundreds of $H$. alpinum plants, but the closest $H$. transsilvanicum plants were ca. 200-300 m away. Therefore, we considered it interesting to test not only the putative hybrid origin of these plants, but also to infer the direction of the hybridization. Moreover, we wanted to test the suitability of several molecular markers that had not been used in our previous study (Mráz et al. 2005), namely amplified fragment length polymorphism (AFLP) and nuclear internal transcribed spacer (ITS) sequencing, for inferring putative hybridization. In addition, allozyme analysis was used as it proved to be a suitable tool for testing the hybrid origin of $H . \times k r a s a n i$ (Mráz et al. 2005).

\section{Materials and methods}

\section{Plant material}

Putative hybrid plants as well as the supposed parental taxa were collected on Mt. Bogolin (Romania) and other localities in the Ukraine and Romania (Table 1). The putative hybrids were cultivated in the experimental field of the Botanical Garden of the P. J. Šafárik University in Košice and in the greenhouse at the Institute of Botany, Academy of Sciences of the Czech Republic, in Průhonice to infer ploidy level and allozyme variation. Voucher specimens are deposited in the herbarium P. Mráz and at the Institute of Botany, Průhonice (PRA). We also included two previously corroborated natural and two artificial $H$. $\times$ krasani hybrids arising from control crosses between $H$. alpinum and $H$. transsilvanicum in the analyses (cf. Mráz 2003; Mráz et al. 2005). Details about all plants studied are given in Table 1.

DNA-ploidy level and chromosome number

DNA-ploidy level was estimated by flow cytometry (FCM) for three putative hybrids from Mt. Bogolin. These analyses and chromosome counting were performed according to the methods given in Mráz et al. (2009) with the exception of the cytometrical standard for which diploid Hieracium umbellatum (cultivation number X18/3) instead of Zea mays was used. Because the peak of the putative hybrid PM 
Table 1 Origin of Hieracium plant material and number of plants per population used for the respective analyses

\begin{tabular}{|c|c|c|c|c|c|c|}
\hline Taxon & Locality/note & AFLP & ITS & cpDNA & Allozymes & $\begin{array}{l}\text { FCM/ } \\
\text { karyology }\end{array}$ \\
\hline \multirow[t]{3}{*}{ H. alpinum } & $\begin{array}{l}\text { Romania, Munţii Bistriţei, Mt. Pietrosul Bogolin, } 1,720 \mathrm{~m} \text { a.s.1., } 47^{\circ} 23.1^{\prime} \mathrm{N}, \\
25^{\circ} 32.16^{\prime} \text { E, coll. P. Mráz and J. Chrtek, } 16 \text { July } 2004 \text { \& A. Oprea, } 2006\end{array}$ & 10 & & & & \\
\hline & $\begin{array}{l}\text { Ukraine, Chornohora Mts, Polonina Pozhyzhevska, } 48^{\circ} 09.19^{\prime} \mathrm{N}, 24^{\circ} 32.07^{\prime} \\
\text { E, } 1,430 \text { m a.s.1., coll. R. Letz, } 18 \text { July } 2004\end{array}$ & 5 & & & & \\
\hline & $\begin{array}{l}\text { Ukraine, Chornohora Mts, Polonina Breskulska, the saddle between Mt. } \\
\text { Hoverla and Mt. Breskul, } 48^{\circ} 09^{\prime} 10^{\prime \prime} \text { N, } 24^{\circ} 30^{\prime} 15^{\prime \prime} \text { E, } 1,800 \mathrm{~m} \text { a.s.l., coll. } \\
\text { P. Mráz and J. Chrtek, } 23 \text { July } 2003\end{array}$ & & & $1^{\mathrm{a}}$ & $10^{\mathrm{a}}$ & \\
\hline \multirow[t]{3}{*}{ H. ×krasani } & $\begin{array}{l}\text { Romania, Munţii Bistriței, Mt. Pietrosul Bogolin, } 1,720 \mathrm{~m} \text { a.s.1., } 47^{\circ} 23.1^{\prime} \mathrm{N} \text {, } \\
25^{\circ} 32.16^{\prime} \text { E, coll. P. Mráz and J. Chrtek, } 16 \text { July } 2004\end{array}$ & $3^{\mathrm{b}}$ & $3^{\mathrm{b}}$ & $3^{\mathrm{b}}$ & $3^{\mathrm{b}}$ & $3^{\mathrm{b}}$ \\
\hline & $\begin{array}{l}\text { Ukraine, Chornohora Mts, Polonina Breskulska ridge, } 1,410 \mathrm{~m} \text { a.s.l., } \\
48^{\circ} 08^{\prime} 35^{\prime \prime} \mathrm{N}, 24^{\circ} 28^{\prime} 56.7^{\prime \prime} \text { E, coll. P. Mráz and J. Chrtek, } 23 \text { July } 2003\end{array}$ & $2^{\mathrm{c}}$ & $1^{\mathrm{d}}$ & $2^{\mathrm{a}}$ & $3^{\mathrm{a}}$ & \\
\hline & Artificial hybrids $\mathrm{e}^{\mathrm{e}}$ & $2^{\mathrm{f}}$ & $2^{\mathrm{g}}$ & & $1^{\mathrm{h}}$ & \\
\hline \multirow[t]{3}{*}{ H. transsilvanicum } & $\begin{array}{l}\text { Romania, Munţii Rodnei Mts, Mt. Pietrosul Mare, spruce forest, } \\
1,300-1,400 \text { m a.s.l., } 47^{\circ} 39^{\prime} \text { N, } 24^{\circ} 39^{\prime \prime} \text { E, coll. P. Mráz, } 5 \text { July } 2001\end{array}$ & 1 & & & & \\
\hline & $\begin{array}{l}\text { Ukraine, Chornohora Mts, Polonina Breskulska ridge, } 1,410 \mathrm{~m} \text { a.s.l., } \\
48^{\circ} 08^{\prime} 35.0^{\prime \prime} \mathrm{N}, 24^{\circ} 28^{\prime} 56.7^{\prime \prime} \text { E, coll. P. Mráz and J. Chrtek, } 23 \text { July } 2003\end{array}$ & $1^{\mathrm{i}}$ & & & $12^{\mathrm{a}}$ & \\
\hline & $\begin{array}{l}\text { Ukraine, Marmarosh Mts, Mt. Berlebashka, } 1,200 \mathrm{~m} \text { a.s.1., } 47^{\circ} 56^{\prime} 13^{\prime \prime} \mathrm{N}, 24^{\circ} \\
21^{\prime} 31^{\prime \prime} \text { E, coll. J. Zahradníček, } 19 \text { September } 2005\end{array}$ & $2^{\mathrm{j}}$ & & $1^{\mathrm{k}}$ & & \\
\hline
\end{tabular}

a Published data from Mráz et al. (2005)

b Plant codes: PM 1711 (2x), PM 1712 (2x), PM 1713 (4x)

c Plant codes: PM 1399, PM 1400

d Plant code: PM 1399

e For details, see Mráz (2003)

${ }^{\mathrm{f}}$ Plant codes: X5/5, X5/6

g Plant codes: $\mathrm{X} 5 / 5, \mathrm{X} 5 / 10$

${ }^{\text {h }}$ Plant code: X5/6

${ }^{\mathrm{i}}$ Plant code: PM 1406

j Plant codes: H 1077/7, H 1077/10

${ }^{k}$ Plant code: H 1077/10

1713 suggested that the plant was tetraploid, the measurement was repeated and also confirmed by chromosome counting.

\section{Allozyme analysis}

Three plants of $H . \times$ krasani from Mt. Bogolin (Romania) and one artificial hybrid from control crosses (cf. Mráz 2003) were analyzed; further data from Mráz et al. (2005) were included for comparison (see Tables 1, 2). Extraction, electrophoresis, and staining followed the methods described in Štorchová et al. (2002). The following enzyme systems were examined and allelically interpreted: AAT (aspartate aminotransferase, EC 2.6.1.1, dimeric), LAP (leucine aminopeptidase, EC 3.4.11.1, monomeric), MDH (malate dehydrogenase, EC 1.1.1.37, dimeric), 6PGD (6-phosphogluconate dehydrogenase, EC 1.1.1.44, dimeric), PGM (phosphoglucomutase, EC 5.4.2.2, monomeric), and SKD (shikimic acid dehydrogenase, EC 1.1.1.25, monomeric).

\section{DNA extraction}

The leaves of cultivated plants or plants from the field were dried in silica gel and stored at room temperature. In rare cases, herbarium specimens were used. Total DNA was extracted from $10-15 \mathrm{mg}$ of silica-dried leaf tissue with the DNeasy 96 Plant Kit (Qiagen), following the manufacturer's protocol or by the method of Štorchová et al. (2000).

\section{AFLPs}

The AFLP procedure followed Mráz et al. (2007) except for the choice of selective primers; combinations EcoRIAAG/MseI-CAG and EcoRI-ACC/MseI-CTG were used. 
Table 2 Allozyme genotypes and their frequencies of two parental taxa Hieracium alpinum and H. transsilvanicum and their hybrid H. $\times$ krasani

\begin{tabular}{|c|c|c|c|c|c|c|c|c|c|}
\hline Taxon (locality/no. of plants) & Aat-2 & Adh-1 & Lap-1 & Lap-2 & $M d h$ & 6-Pgdh-1 & 6-Pgdh-2 & Pgm-1 & Skd \\
\hline H. alpinum (Chornohora Mts/10) & bb 1.00 & $\begin{array}{l}\text { ab } 0.10 \\
\text { bb } 0.90\end{array}$ & 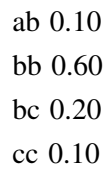 & $\begin{array}{l}\text { aa } 0.40 \\
\text { ab } 0.60\end{array}$ & - & aa 1.00 & bb 1.00 & ac 1.00 & aa 1.00 \\
\hline H. transsilvanicum (Chornohora Mts/12) & 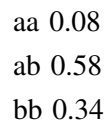 & bb 1.00 & & $\begin{array}{l}\text { aa } 0.92 \\
\text { ab } 0.08\end{array}$ & - & $\begin{array}{l}\text { bb } 0.58 \\
\text { bc } 0.42\end{array}$ & $\begin{array}{l}\text { aa } 0.08 \\
\text { bb } 0.92\end{array}$ & ab 1.00 & $\begin{array}{l}\text { bb } 0.25 \\
\text { bc } 0.42 \\
\text { cc } 0.33\end{array}$ \\
\hline H. $\times$ krasani $($ Chornohora Mts/3) & bb 1.00 & bb 1.00 & bb 1.00 & ab 1.00 & - & bc 1.00 & ab 1.00 & ac 1.00 & ac 1.00 \\
\hline H. $\times$ krasani $(2 \mathrm{x})($ Munţii Bistriţei/2) & $\begin{array}{l}\text { ab } 0.50 \\
\text { bb } 0.50\end{array}$ & - & $\begin{array}{l}\text { aa } 0.50 \\
\text { bb } 0.50\end{array}$ & - & ab 1.00 & bc 1.00 & bb 1.00 & aa 1.00 & $\begin{array}{l}\text { ab } 0.50 \\
\text { ac } 0.50\end{array}$ \\
\hline H. $\times$ krasani $(4 \mathrm{x})($ Munţii Bistriţei/1) & aabb & - & aaaa & - & aabb & bccc & bbbb & aaaa & aaac \\
\hline H. $\times$ krasani (artificial hybrid/1) & $\mathrm{ab}$ & - & $\mathrm{bb}$ & - & $a b$ & $\mathrm{bc}$ & $\mathrm{bb}$ & aa & $\mathrm{ac}$ \\
\hline
\end{tabular}

Number of plants analyzed are given in parentheses. Missing data are indicated by '-'. Bands of Lap-1 were not present in H. transsilvanicum

Fragments of a size range of $50-500$ bp were manually scored with GENMAPPER version 3.1 (Applied Biosystems) for their presence/absence. Two samples, one artificial hybrid and one $H$. alpinum, from a total of 26 were analyzed twice to test for reproducibility of the AFLP analysis. For a list of samples, see Table 1. For further analysis, 70 polymorphic markers were kept; monomorphic and non-reproducible AFLP bands were removed from the dataset. The relationships between the putative parental taxa and their hybrid were inferred by principal coordinate analysis (PCO) implemented in the ade4 package (Chessel et al. 2004) in the Rcran environment (R Development Core Team 2006). The distance matrix was based on the Jaccard coefficient of similarity.

\section{Nuclear DNA sequencing}

We chose the internal transcribed spacer (ITS) of ribosomal nuclear DNA to test the hybridogeneous origin of the putative hybrid plants as this marker is inherited biparentally, and, in the case of absence of sequence homogenization, it is suitable for inferring hybridization (Sang et al. 1995; Campbell et al. 1997). The ITS region was amplified using the primers ITS A and ITS B (Blattner 1999) in a $25 \mu \mathrm{l}$ reaction volume containing $1 \mu \mathrm{l}$ of genomic DNA (10-35 ng), $2.5 \mu \mathrm{M}$ buffer $(10 \times$ Buffer II, Applied Biosystems), $1.5 \mathrm{mM} \mathrm{MgCl}_{2}, 0.2 \mu \mathrm{M}$ of each dNTP, $0.2 \mu \mathrm{M}$ of each primer, $0.25 \mu \mathrm{M}$ BSA, and $0.5 \mathrm{U}$ of AmpliTaq Gold DNA polymerase (Applied Biosystems). The cycling profile included an initial denaturation step at $95^{\circ} \mathrm{C} / 10 \mathrm{~min}$ followed by 28 cycles of $95^{\circ} \mathrm{C} / 30 \mathrm{~s}, 52^{\circ} \mathrm{C} / 30 \mathrm{~s}, 72^{\circ} \mathrm{C} / 1 \mathrm{~min}$, and ended with $72^{\circ} \mathrm{C} / 10$ min and $4^{\circ} \mathrm{C}$ thereafter. PCR products were purified using the QIAquick Gel Extraction Kit. Sequencing was performed in both directions using BigDye Terminator V 3.1 (Applied Biosystems). The samples were run on an ABI PRISM ${ }^{\circledR} 3100$ Genetic Analyzer. Sequences were assembled and edited using Seqscape 2.5.0 (Applied Biosystems). The presence of heterozygous sites (intra-individual polymorphisms) in ITS1 and ITS2 was assessed in most cases on both forward and reverse strands according to Aguilar and Feliner (2003). Some polymorphic sites could only be determined from one strand, especially at the beginning where saturated peaks hampered the correct reading of the sequences. In total we sequenced three hybrids previously corroborated by other methods (Mráz et al. 2005) and the three new putative hybrids (Table 1). Their ITS sequences were compared to published ITS sequences of the parental taxa from the same area (Fehrer et al. 2007).

\section{Chloroplast DNA}

The $\operatorname{trn} \mathrm{T}$-L intergenic spacer of chloroplast DNA was used to distinguish between $H$. alpinum and $H$. transsilvanicum and to identify the chloroplast donor of the putative hybrid plants. Two accessions of each $H$. alpinum (GenBank acc. no. AY512556, EU867711) and $H$. transsilvanicum (AY512557, EU867743) from Mráz et al. (2005) and Fehrer et al. (2009) had identical sequences. Based on these sequences, EcoRI was chosen as a restriction enzyme that produced discriminating patterns, and the hybrid accessions were subjected to PCR-RFLPs along with the parental species for comparison (see Table 1). PCRs, sequencing, and restriction digests were done as described in Mráz et al. (2005). Chloroplast DNA had been shown 
previously to be maternally transmitted in these two species based on the examination of artificial hybrids from reciprocal crosses (Mráz et al. 2005).

\section{Results}

Ploidy level and chromosome number

The DNA-ploidy level of two putative hybrids from Mt. Bogolin (PM 1711 and PM 1712) was diploid $(2 \mathrm{n} \sim 2 \mathrm{x} \sim 18)$. The third putative hybrid PM 1713 was cytometrically determined to be a tetraploid (relative peak position of sample to standard plant, diploid $H$. umbellatum, was 1.8), which was later confirmed by chromosome counting $(2 \mathrm{n}=4 \mathrm{x}=36)$.

Allozyme analysis

Six enzyme systems with ten loci were investigated in four wild plants of $H$. $\times$ krasani and one artificial hybrid between $H$. alpinum and $H$. transsilvanicum. Three loci were excluded from further analyses: Aat- 1 (monomorphic in all plants studied), Pgm-2, and Lap-2 (both with low enzyme activity). Genotype frequencies of each locus for both parental species (data from Mráz et al. 2005) and both natural and artificial hybrid plants $(H . \times$ krasani, current data and data from Mráz et al. 2005) are given in Table 2. In total, five different multilocus genotypes were detected in plants of $H . \times$ krasani: while the three plants from Romania differed from each other in their genotypes, all plants from the Ukraine belonged to one genotype (Mráz et al. 2005), and a further genotype was detected in the artificial hybrid. The hybrid origin of the Romanian plants was clearly indicated by a unique additive pattern in $S k d$ : both alleles a and c were recorded in $H$. xkrasani, while only allele a was present in $H$. alpinum and alleles b and c were found in $H$. transsilvanicum. Moreover, the contribution of $H$. alpinum was indicated by the band of Lap- 1 (in $H$. transsilvanicum the bands were consistently lacking, cf. Mráz et al. 2005).

\section{AFLPs}

The average number of AFLP fragments per individual ranged from 33 to 42 out of 70 polymorphic ones in total (Table 3), with the highest value recorded in an accession of $H$. $\times$ krasani obtained by artificial crossing. While the mean number of AFLP bands per individual was similar in the two putative parental taxa and their putative hybrid, the total number of bands per (notho) taxon was different. Hieracium $\times$ krasani showed many more bands than its parental taxa (59 vs. 45 and 47 fragments, respectively).
This is because the hybrids also displayed bands that were exclusive to each of their parents (Table 3).

The principal coordinate analysis revealed the existence of two well-separated groups of plants belonging to the putative parental taxa. Three putative hybrid plants from Mt. Bogolin as well as four previously corroborated H. $\times$ krasani hybrids (two natural and two artificial ones) occupied an intermediate position (Fig. 1). They exhibited a higher diversity than either parent. Moreover, hybrid plants showed a tendency to cluster according to their geographic (natural hybrids) or experimental origin (artificial hybrids) (see Fig. 1).

ITS polymorphism

Three sequenced accessions of putative hybrid origin from Mt. Bogolin showed the same additive pattern of ITS polymorphism. No indels occurred between the parental species so that the sequences could be read in both directions. Additive characters inferred from superimposed peaks represented those 12 positions that differ between the parental species $H$. alpinum and $H$. transsilvanicum (Table 4). The same pattern was observed in ITS sequences of one already corroborated natural hybrid of $H$. $\times$ krasani from the Ukraine (Mráz et al. 2005), as well as in two artificial hybrids.

\section{Chloroplast DNA analyses}

In contrast to the previously investigated material of H. $\times$ krasani (Mráz et al. 2005) that had H. transsilvanicum as a maternal parent, PCR-RFLPs of the trnT-L intergenic spacer of chloroplast DNA showed that all three hybrid plants from Mt. Bogolin investigated here had obtained their cpDNA from $H$. alpinum, including the tetraploid accession (Fig. 2).

Table 3 Number of AFLP fragments scored in the parental taxa and their hybrid

\begin{tabular}{lcclcc}
\hline Taxon & $\mathrm{N}$ & $\mathrm{TNF}$ & $\mathrm{MNF}$ & $\mathrm{EF}$ & $\mathrm{SF}$ \\
\hline H. alpinum & 15 & 47 & $\begin{array}{l}35.7 \\
(33-38)\end{array}$ & 23 & 24 \\
H. $\times$ krasani & 7 & 59 & $\begin{array}{l}37.7 \\
(34-42)\end{array}$ & 2 & - \\
H. transsilvanicum & 4 & 45 & 33.5 & 21 & 24 \\
& & & $(33-35)$ & &
\end{tabular}

$N$ Number of plants analyzed per taxon, $T N F$ total number of AFLP fragments per taxon, $M N F$ mean number of AFLP fragments per individual plant (range), $E F$ total number of exclusive AFLP fragments per taxon, $S F$ total number of shared AFLP fragments between a particular parental taxon and $H . \times$ krasani 


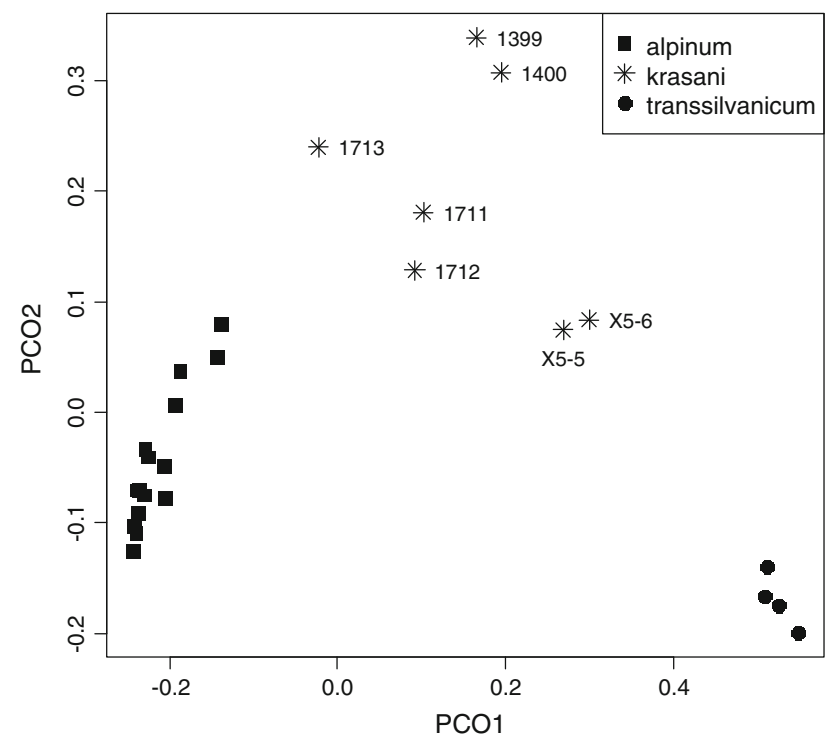

Fig. 1 Principal coordinate analysis (PCO) plot of 26 individuals of hybrid Hieracium $\times$ krasani and its two parental taxa $H$. alpinum and $H$. transsilvanicum based on Jaccard distances calculated on amplified fragment length polymorphism (AFLP) multilocus phenotypes. Hybrid plants are labelled (see Table 1) to show their tendency to cluster according their geographic origin or their origin from the same experimental cross

\section{Discussion}

Molecular evidence for hybrid origin

Our combined molecular approach (nuclear ITS, AFLPs, and allozymes) clearly supports the hybrid origin of three plants from Mt. Bogolin from Hieracium alpinum and H. transsilvanicum. Complete character additivity of ITS polymorphism and no sign of homogenization towards the one or other parental copy were revealed by direct sequencing. Therefore, this marker seems to be very reliable for the assessment of recent hybridization in the genus Hieracium. The lack of concerted evolution in natural and artificial $H . \times$ krasani might be explained by the very

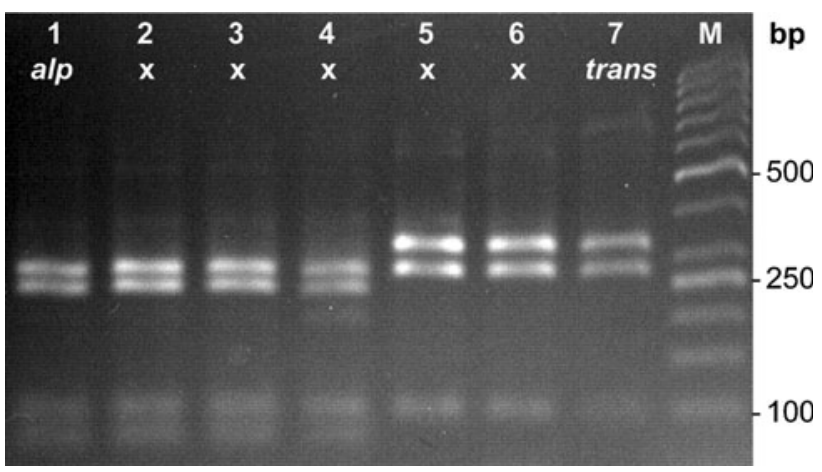

Fig. 2 PCR-RFLP of the chloroplast trnT-L intergenic spacer with EcoRI. $M$ DNA size standard, alp H. alpinum, $x H . \times$ krasani, trans H. transsilvanicum. All hybrid accessions from Mt Bogolin (lanes 2-4) show the same pattern as H. alpinum indicating that this species was their maternal parent. Hybrids from the Ukraine (lanes 5-6) from Mráz et al. (2005) with $H$. transsilvanicum as their maternal parent are included for comparison

recent origin and sterility of putatively $\mathrm{F}_{1}$ hybrids (cf. Mráz et al. 2005; Mráz and Paule 2006). However, a similar pattern-retention of intra-individual external transcribed spacer (ETS) polymorphic sites-has been observed not only in old polyploid Hieracium, in which apomictic reproduction might efficiently prevent concerted evolution of multicopy genes as has been observed also in other apomictic genera (cf. Campbell et al. 1997; Záveská Drábková et al. 2009), but also in some diploid sexual Hieracium taxa that are fully fertile, but apparently of ancient hybrid origin (Fehrer et al. 2009). This might suggest that concerted evolution is not a very common and efficient mechanism in Hieracium s.str. In any case, early generation hybrids (most probably $F_{1}$ hybrids in our case) can be expected to have unskewed ratios of parental ITS variants as reflected by their sequencing profiles.

With respect to AFLPs and allozymes, the three hybrid plants from Mt. Bogolin were detected to be genetically different and thus to have originated from independent crosses of the parental taxa. This is not surprising given

Table 4 Additive pattern of ITS polymorphism in natural and artificial hybrid plants of Hieracium $\times$ krasani in comparison to the parental taxa

\begin{tabular}{|c|c|c|c|c|c|c|c|c|c|c|c|c|}
\hline \multirow[t]{2}{*}{ Taxon } & \multicolumn{12}{|c|}{ Alignment position } \\
\hline & 46 & 61 & 73 & 74 & 103 & 131 & 136 & 228 & 494 & 562 & 580 & 615 \\
\hline H. alpinum ${ }^{\mathrm{a}}$ & $\mathrm{C}$ & $\mathrm{C}$ & $\mathrm{C}$ & $\mathrm{C}$ & $\mathrm{C}$ & $\mathrm{C}$ & $\mathrm{C} / \mathrm{Y}^{\mathrm{d}}$ & A & A & $\mathrm{T}$ & A & $\mathrm{T}$ \\
\hline H. $\times$ krasani $^{\mathrm{b}}$ & $\mathrm{Y}$ & $\mathrm{Y}$ & M & $\mathrm{Y}$ & M & $\mathrm{Y}$ & $\mathrm{Y}$ & W & W & $\mathrm{Y}$ & W & $\mathrm{Y}$ \\
\hline H. transsilvanicum ${ }^{\mathrm{c}}$ & $\mathrm{T}$ & $\mathrm{T}$ & A & $\mathrm{T}$ & A & $\mathrm{T}$ & $\mathrm{T}$ & $\mathrm{T}$ & $\mathrm{T}$ & $\mathrm{C}$ & $\mathrm{T}$ & $\mathrm{C}$ \\
\hline
\end{tabular}

a Gen Bank accession no AJ633429 (Fehrer et al. 2007)

b Gen Bank accession no HM627291 (this study, PM1712, the sequence of this accession was submitted to the Gen Bank only, as two remaining sequenced samples had the same sequence)

${ }^{\mathrm{c}}$ Gen Bank accession no AJ633427 (Fehrer et al. 2007)

${ }^{\mathrm{d}}$ One published ITS sequence of Hieracium alpinum (AJ633429) showed C at this position, but several accessions from the Eastern Carpathians displayed an intra-individual polymorphism C + T (Y) (Mráz et al., unpubl. data) 
that these plants were sampled from different places at the locality and one of them even had a different ploidy level. In our previous paper (Mráz et al. 2005) we reported three plants of $H . \times k$ rasani from the Ukraine that shared the same multilocus allozyme pattern. All plants were collected at the same microsite $(30 \times 30 \mathrm{~cm})$ and therefore we originally thought that they might represent a single clone (Mráz et al. 2005). In the present study, we re-analyzed these plants (PM 1399 and PM 1400, see Table 1) using AFLPs, and they also turned out to be genetically different from each other, suggesting a more discriminative power for the AFLPs in comparison with allozymes. The utility of AFLP markers for inferring the phylogeographic structure in some mountain taxa belonging to the Hieracium sect. Cernua has been shown by Ronikier and Szeląg (2008). The AFLPs have been applied also in rare H. cyathis and closely related taxa in order to test the genetic integrity of this species (Rich et al. 2008). Here we demonstrate the usefulness of amplified fragment length polymorphism also for the detection of interspecific Hieracium hybrids.

\section{Evidence for bidirectional gene flow}

Despite the independent origin of several hybrid plants at one locality (Mt. Bogolin, Romania), all shared the same chloroplast haplotype, which was obtained from $H$. alpinum as their maternal parent. In contrast, three hybrid plants from two localities from the Romanian (Munţii Rodnei) and Ukrainian Eastern Carpathians had H. transsilvanicum as their maternal parent (Mráz et al. 2005). In the latter case, many $H$. transsilvanicum plants were found at both sites while the second parental species, $H$. alpinum, was either completely absent or extremely rare. On the contrary, the hybrid individuals from Mt. Bogolin investigated here exhibited the $H$. alpinum haplotype and cooccurred with hundreds of $H$. alpinum plants. This might suggest that the direction of the hybridization could be influenced by the dominance of the maternal taxon at a given site. In our previous paper (Mráz et al. 2005) we discussed in detail this unexpected pattern, where we originally assumed putatively longer distance dispersal by seeds than by pollen. However, our previous and present data contradict this assumption. Pollen movement might be in fact more efficient than we previously thought, and many of the hybrid seeds probably drop to the ground near the maternal parents without long dispersal. A similar pattern has been observed in the genus Asclepias, which is also adapted for long distance seed dispersal (Broyles 2002). Furthermore, we cannot exclude a potential advantageous effect the maternal parent might have on the hybrid's adaptation to the same habitat. Indeed, artificial $F_{1}$ hybrids from reciprocal crosses as well as natural
Hieracium hybrids showed-despite a high degree of morphological intermediacy between both parental taxatendencies to be more similar to the maternal species (Mráz et al. 2005; Mráz and Paule 2006). Given the strong differences in light preferences and thus ecophysiological tolerance between the two parental taxa $(H$. alpinum is an alpine strict heliophyte species while $H$. transsilvanicum is a sciophyte taxon growing in forests and forest clearings), the hybrid seedlings having the "wrong" maternal taxon might be selected against when growing in the "wrong" habitat. The two hypotheses are not mutually exclusive and can explain the observed pattern.

\section{Spontaneous polyploidization}

One hybrid plant from Mt. Bogolin was tetraploid. Given that both parental taxa are diploid in this region (Pashuk 1987; Chrtek 1996, 1997; Mráz 2001, 2003; Mráz and Szeląg 2004; Mráz et al. 2005, 2009; Chrtek et al. 2006), and that the other two hybrid plants as well as other natural and artificial Hieracium hybrids originating from diploid $\times$ diploid crosses were also diploid (Mráz et al. 2005; Mráz and Paule 2006; Chrtek et al. 2006), this was a quite surprising finding. Generally, two main pathways leading to polyploidy are distinguished: direct somatic doubling acting at the zygote or young embryo stages, and-more frequent and thus more important-polyploidization through the production of unreduced $2 \mathrm{n}$ gametes (Ramsey and Schemske 1998). In this case, a new polyploid cytotype can arise through the fusion of two unreduced gametes $(2 \mathrm{n} \times 2 \mathrm{n})$ via a one-step model, or-likely more frequently - through a so-called "triploid bridge" $(2 \mathrm{n} \times \mathrm{n}$, cf. Harlan and de Wet 1975). As triploid plants usually have low fertility due to an unbalanced chromosome pairing during meiosis and may encounter problems with endosperm formation (triploid block), a second step, namely a backcross to one of the parental taxa or a cross with another hybrid plant or selfing is needed, resulting in a more stable tetraploid cytotype (Ramsey and Schemske 1998). Our allozyme data suggest that the "unreduced gametes" pathway was involved in the origin of the tetraploid hybrid (PM 1713) with subsequent backcrossing to H. alpinum (or to another hybrid plant) rather than direct somatic duplication. Such a scenario is supported by unbalanced heterozygosity observed at the $S k d$ locus in the tetraploid plant (allelic composition aaac). The allele $S k d-a$ is known only in $H$. alpinum while $S k d-c$ and $S k d-b$ alleles are specific to H. transsilvanicum (see also Mráz et al. 2005). In the case of direct somatic doubling, the allopolyploid hybrid should exhibit only homozygous and/or balanced heterozygous loci. Although the ITS electropherogram from direct sequencing of the tetraploid plant did not show a higher contribution (higher peaks) of $H$. alpinum ITS copies, this 
may be due to locus loss following hybridization or else as a result of PCR drift (Wagner et al. 1994). Therefore, the allozyme data can be considered as more reliable for the inference of the tetraploid's genomic composition.

A triploid intermediate step implies the participation of unreduced gametes. Unreduced gametes can be formed in the parental diploid taxa, as has been shown in many angiosperms (e.g., Ortiz 1997; Bretagnolle 2001; Grant 2002) or in primary diploid hybrids. In the latter case, however, the production of unreduced gametes is ca. 50 times higher than in nonhybrids (Ramsey and Schemske 1998). Hence, interspecific homoploid hybrids seem to play a crucial role in polyploid evolution. To the best of our knowledge, we have no indication of the presence of unreduced pollen either in diploid Hieracium species or in their diploid interspecific hybrids, as they formed only a high quantity of homogeneously sized pollen, and no irregular pollen suggesting a different amount of genome has been recorded as yet (Mráz et al. 2002, 2009; Chrtek et al. 2006; Mráz and Paule 2006). On the other hand, there is no information on the frequency of unreduced ovules in diploid Hieracium, which might be more important than unreduced pollen as it was reported in closely related polyploid Pilosella (cf. Peckert and Chrtek 2006).

Polyploidization is traditionally considered as an important step following interspecific hybridization in order to restore the chromosome pairing and thus providing the hybrids with reproductive assurance (Ramsey and Schemske 1998). According to this, one would expect a higher fertility in our tetraploid hybrid than in natural and artificial diploid hybrids, which proved to be either completely seed sterile or produced only a few seeds (Mráz et al. 2005; Mráz and Paule 2006; Chrtek et al. 2006). Unfortunately, it was neither possible to verify the seed set of the tetraploid hybrid nor pollen formation as the flower heads aborted soon after transfer to the experimental field in the botanical garden and the plant did not survive the winter 2004/2005. Consequently, we could not test even its breeding system, which could offer very important information, as all natural Hieracium polyploids studied so far reproduced solely apomictically (e.g., Chrtek 1997; Mráz and Szeląg 2004; Chrtek et al. 2009). In contrast, experimental hybridization between sexual diploid Hieracium pojoritense Woł. and apomictic tetraploid $H$. dentatum s.l. as a pollen donor produced a triploid, morphologically intermediate hybrid that was completely seed sterile (Mráz 2003; Mráz unpubl. data). Thus, neither the polyploid status of the hybrid plant nor the involvement of one apomictically reproducing parent assured independent seed formation in this triploid. The possible reasons for seed set failure in this triploid hybrid might involve problems with endosperm formation (Vinkenoog et al. 2003) and, maybe to a lesser extent, genomic incompatibilities between divergent parental taxa. In this light, it is possible that the tetraploid $H$. $\times$ krasani plant was sterile, too.

In conclusion, our study showed further evidence of recent interspecific hybridization in the genus Hieracium at the diploid level. Moreover, combined methodological approaches (karyology, allozymes, AFLPs, and nuclear and plastid sequences) allowed us to prove not only the hybrid origin of the plants studied, but also to determine the direction of hybridization and to suggest a possible origin of a rare allotetraploid plant. To our best knowledge, this is the first case of spontaneous polyploidization following interspecific hybridization between two divergent taxa in the genus Hieracium. Given that most Hieracium taxa are polyploids reproducing asexually, our findings might represent an important step towards a better understanding of polyploid evolution in Hieracium.

Acknowledgments Authors are thankful to R. Letz, A. Oprea, and J. Zahradníček for their kind help with collecting of plant material. I. Plačková performed the allozyme analyses; D. Rioux, M. Loncová, P. Caklová and A. Yadollahi helped with the labwork. This study was performed as a part of Marie Curie Intra-European fellowship (no. 10961 to P.M.). The work was also supported by the Czech Science Foundation (grant no. P506/10/1363 to J.C.), the Academy of Sciences of the Czech Republic (grant no. AV0Z60050516 to J.C. and J.F.) and the Ministry of Education, Youth and Sports of the Czech Republic (grant no. 0021620828 to J.C.).

\section{References}

Aguilar JF, Feliner GN (2003) Additive polymorphisms and reticulation in an ITS phylogeny of thrifts (Armeria, Plumbaginaceae). Mol Phylogen Evol 28:430-447

Blattner FR (1999) Direct amplification of the entire ITS region from poorly preserved plant material using recombinant PCR. Biotechniques 27:1180-1186

Bretagnolle F (2001) Pollen production and spontaneous polyploidization in diploid populations of Anthoxanthum alpinum. Biol J Linn Soc 72:241-247

Broyles SB (2002) Hybrid bridges to gene flow: a case study in milkweeds (Asclepias). Evolution 56:1943-1953

Campbell CS, Wojciechowski MF, Baldwin BG, Alice LA, Donoghue MJ (1997) Persistent nuclear ribosomal DNA sequence polymorphism in the Amelanchier agamic complex (Rosaceae). Mol Biol Evol 14:81-90

Chessel D, Dufour AB, Thioulouse J (2004) The ade4 package-I-Onetable methods. R News 4:5-10

Chrtek J Jr (1996) Chromosome numbers in selected species of Hieracium (Compositae) in the Sudeten Mts and Western and Ukrainian Eastern Carpathians. Fragm Florist Geobot 41:783790

Chrtek J Jr (1997) Taxonomy of the Hieracium alpinum group in the Sudeten Mts, the West and the Ukrainian East Carpathians. Folia Geobot Phytotax 32:69-97

Chrtek J Jr, Mráz P, Severa M (2004) Chromosome numbers in selected species of Hieracium s. str. (Hieracium subgen. Hieracium) in the Western Carpathians. Preslia 76:119-139

Chrtek J Jr, Mráz P, Sennikov AN (2006) Hieracium $\times$ grofae-a rediscovered diploid hybrid from the Ukrainian Carpathians. Biologia (Bratislava) 61:365-373 
Chrtek J Jr, Mráz P, Zahradníček J, Mateo G, Szeląg Z (2007) Chromosome numbers and DNA-ploidy levels of selected species of Hieracium s.str. (Asteraceae). Folia Geobot 42:411430

Chrtek J Jr, Zahradníček J, Krak K, Fehrer J (2009) Genome size in Hieracium subgenus Hieracium (Asteraceae) is strongly correlated with major phylogenetic groups. Ann Bot 104:161-178

Fehrer J, Gemeinholzer B, Chrtek J, Bräutigam S (2007) Incongruent plastid and nuclear DNA phylogenies reveal ancient intergeneric hybridization in Pilosella hawkweeds (Hieracium, Cichorieae, Asteraceae). Mol Phylogen Evol 42:347-361

Fehrer J, Krak K, Chrtek J Jr (2009) Intra-individual polymorphism in diploid and apomictic polyploid hawkweeds (Hieracium, Lactuceae, Asteraceae): disentangling phylogenetic signal, reticulation and noise. BMC Evol Biol 9:239

Grant V (2002) Frequency of spontaneous amphiploids in Gilia (Polemoniaceae) hybrids. Am J Bot 89:1197-1202

Gustafsson $\AA$ (1946) Apomixis in higher plants. Part I. The mechanism of apomixis. Acta Univ Lund 42:1-67

Harlan JR, de Wet JMJ (1975) On O. Winge and a prayer: the origins of polyploidy. Bot Rev 41:361-390

Merxmüller H (1975) Diploide Hieracien. Anal Inst Bot Cavanilles 32:189-196

Mráz P (2001) Chromosome numbers in selected species of Hieracium sect. Alpina (Asteraceae) from Central and Eastern Europe. Folia Geobot 36:321-322

Mráz P (2003) Mentor effects in the genus Hieracium s. str. (Compositae, Lactuceae). Folia Geobot 38:345-350

Mráz P, Paule J (2006) Experimental hybridization in the genus Hieracium s. str. (Asteraceae): crosses between selected diploid taxa. Preslia 78:1-26

Mráz P, Szeląg Z (2004) Chromosome numbers and reproductive systems in selected species of Hieracium and Pilosella (Asteraceae) from Romania. Ann Bot Fenn 41:405-414

Mráz P, Tomčíková D (2004) Experimental hybridization in the genus Hieracium s. str.-crosses between diploid H. umbellatum and triploid H. sabaudum. Thaiszia 14(Suppl 1):15-16

Mráz P, Kovalčíková K, Marhold K (2002) Pollen shapes and size in Hieracium and related genera. In: Gutterman W (ed) Contribution abstracts (lectures and posters) from 6th Hieracium workshop, Hirschegg, Kleinwalsertal (Österreich). Institut für Botanik der Universität Wien, Wien, p 27

Mráz P, Chrtek J, Fehrer J, Plačková I (2005) Rare recent natural hybridization in the genus Hieracium s. str.-evidence from morphology, allozymes and chloroplast DNA. Pl Syst Evol 255:177-192

Mráz P, Gaudeul M, Rioux D, Gielly L, Choler P, Taberlet P, IntraBioDiv Consortium (2007) Genetic structure of Hypochaeris uniflora (Asteraceae) suggests vicariance in the Carpathians and rapid post-glacial colonization of the Alps from an Eastern Alpine refugium. J Biogeogr 34:2100-2114

Mráz P, Chrtek J, Šingliarová B (2009) Geographical parthenogenesis, genome size variation and pollen production in the arcticalpine species Hieracium alpinum. Bot Helv 119:41-51

Nogler GA (1984) Gametophytic apomixis. In: Johri BM (ed) Embryology of angiosperms. Springer, Berlin, pp 475-518

Ortiz R (1997) Occurrence and inheritance of $2 n$ pollen in Musa. Ann Bot 79:449-453
Pashuk KT (1987) Khromozomnye chisla vidov subalpiïskogo poyasa Chernogory (Ukrainskie Karpaty) [Chromosome numbers of species of subalpine belt of Chernogora (Ukrainian Carpathians)]. Bot Zhurn (Moscow and Leningrad) 72:1069-1074

Peckert T, Chrtek J (2006) Mating interactions between coexisting diploid, triploid and tetraploid cytotypes of Hieracium echioides (Asteraceae). Folia Geobot 41:323-334

Ramsey J, Schemske DW (1998) Pathways, mechanisms, and rates of polyploid formation in flowering plants. Annu Rev Ecol Syst 29:467-501

Rich TCG, McDonnell EJ, Lledó MD (2008) Conservation of Britain's biodiversity: the case of Hieracium cyathis (Asteraceae) and its relation to other apomictic taxa. Bot J Linn Soc 156:669-680

Ronikier M, Szeląg Z (2008) Differentiation among disjunct populations of agamospermous species of Hieracium section Cernua (Asteraceae) in Central European subalpine habitats. Bot J Linn Soc 158:93-105

Sang T, Crawford DJ, Stuessy TF (1995) Documentation of reticulate evolution in peonies (Paeonia) using internal transcribed spacer sequences of nuclear ribosomal DNA: implications for biogeography and concerted evolution. Proc Natl Acad Sci USA 92:6813-6817

Schuhwerk F (1996) Published chromosome counts in Hieracium. http://www.botanischestaatssammlung.de/projects/chrzlit.html

Skawińska R (1963) Apomixis in Hieracium alpinum L. Acta Biol Cracov 5(1962):7-14

Slade K, Rich TCG (2007) Pollen studies in British Hieracium sect. Alpina (Asteraceae). Watsonia 26:443-450

Štorchová H, Hrdličková R, Chrtek J Jr, Tetera M, Fitze D, Fehrer J (2000) An improved method of DNA isolation from plants collected in the field and conserved in saturated $\mathrm{NaCl} / \mathrm{CTAB}$ solution. Taxon 49:79-84

Štorchová H, Chrtek J Jr, Bartish IV, Tetera M, Kirschner J, Štěpánek J (2002) Genetic variation in agamospermous taxa of Hieracium sect. Alpina (Compositae) in the Tatry Mts. (Slovakia). Pl Syst Evol 235:1-17

R Development Core Team (ed) (2006) R: a language and environment for statistical computing. R Foundation for Statistical Computing, Vienna

Tyler T, Jönsson J (2009) Ploidy level analysis of apomictic Hieracium (Asteraceae) reveal unexpected patterns and variation. Nord J Bot 27:490-502

Vinkenoog R, Bushell C, Spielman M, Adams S, Dickinson HG, Scott RJ (2003) Genomic imprinting and endosperm development in flowering plants. Mol Biotechnol 25:49-184

Wagner A, Blackstone N, Cartwright P, Dick M, Misof B, Snow P, Wagner GP, Bartels J, Murtha M, Pendleton J (1994) Surveys of gene families using polymerase chain reaction: PCR selection and drift. Syst Biol 43:250-261

Zahn KH (1921-1923) Compositae-Hieracium. In: Engler A (ed) Das Pflanzenreich IV/280. Wilhelm Engelmann, Leipzig

Záveská Drábková L, Kirschner J, Štěpánek J, Záveský L, Vlček Č (2009) Analysis of nrDNA polymorphism in closely related diploid sexual, tetraploid sexual and polyploid agamospermous species. Pl Syst Evol 278:67-85 